\title{
A REDE LABORATORIAL DE SAÚDE PÚBLICA E O SUS*
}

\author{
Ana Rosa dos Santos ${ }^{1}$
}

São apresentados os antecedentes que permitiram a criação de uma rede de laboratórios de saúde pública no Brasil na década de 70. Essa rede existe até os dias de hoje, apesar das intercorrências políticas e administrativas as quais esteve exposto o setor de saúde nos últimos anos. O modelo assistencial concebido originalmente, de forma regionalizada e hierarquizada, vem sendo mantido, devendo ser adequado aos principios e diretrizes do Sistema Único de Saúde (SUS) nas esferas municipal, estadual e federal do governo. O nível local é a unidade mais simples, com atividades básicas necessárias aos programas de saúde local. Ao nível estadual (LACENS) cabe a coordenação da rede estadual, inclusive dos laboratórios regionais dentro da sua competência legal, e ao nivel federal cabe a coordenação das redes que compõem o Sistema Nacional de Laboratórios de Saúde Pública/SNLSP.

\section{Antecedentes}

Dentro da estrutura de saúde, são relevantes os serviços que possibilitam o conhecimento e a análise dos conjuntos de dados laboratoriais em suporte às açóes de vigilância epidemiológica e de vigilância sanitária, campos de atuação da saúde pública. Os Laboratórios de Saúde Pública são as unidades de prestaçāo de serviços que têm como atividade básica a execução de exames laboratoriais para identificaçāo de agentes etiológicos de determinados quadros nosológicos, o monitoramento de açóes de controle sanitário e a participação em inquéritos epidemiológicos. Outras atividades de importância são a padronização de métodos e técnicas de diagnóstico e a supervisão e treinamento de recursos humanos.

A decisão política de organizar-se uma rede nacional de laboratórios de saúde pública

${ }^{1}$ Coondenadora COLAB/CENEPI/FNS

* hrtp://www.fns.gov.br/acoes/laboratorio/lab.htm foi tomada na III Reunião Especial de Ministros da Saúde das Américas, realizada em 1972, no Chile. Naquela reunião, procedeu-se à análise da situação dos laboratórios existentes no Hemisfério Sul e constatou-se a deficiência desse setor que, no caso brasileiro, dispunha de apenas 27 unidades laboratoriais, das quais 17 se encontravam localizadas no Estado de São Paulo.

A importância atribuída à organização de uma rede nacional de laboratórios foi reafirmada, no Brasil, com a constituição de um grupo de trabalho (Portaria Ministerial no 118 , de 30/3/76), diretamente subordinado ao Ministro da Saúde, com a competência de elaborar e implantar um programa voltado à sua implementação.

Originalmente, ficou definido nesse programa que a Rede Nacional seria integrada por laboratórios a serem instalados e/ou 
redimensionados, pertencentes à União e aos Estados, num total de 509 unidades, sendo 420 locais, 65 regionais e 24 centrais. De acordo com a estratégia adotada para o seu desenvolvimento, coube ao Ministério da Saúde o suporte financeiro necessário à adequação da área física $\mathrm{e}$ à edificação das unidades, a aquisição de equipamentos e de insumos básicos e o treinamento de recursos humanos, no Instituto Adolfo Lutz, de São Paulo. Aos Estados competiu a contrataçáo de pessoal e o gerenciamento, nas suas respectivas esferas de atuação, para a execução do programa. No período de implantação da rede (1976/79), foram treinados, no Instituto Adolfo Lutz, técnicos de todas as Unidades Federadas, nas áreas de biologia médica, bromatologia e química.

As ações do grupo de trabalho constituído em 1973 foram assumidas, em 1977, pela Secretaria Nacional de Açóes Básicas de Saúde (SNABS) do Ministério da Saúde e, mais especificamente, pela Divisão Nacional de Laboratórios de Saúde Pública (DNLSP), por força de Portaria Ministerial (no 425, de $26 / 10 / 77$ ), que aprovou o regimento interno daquela Secretaria.

A organização e o funcionamento do Sistema Nacional de Laboratórios de Saúde Pública (SNLSP) foram disciplinados por meio da Portaria Ministerial no 280, de julho de 1977. Além da instituição do SNLSP, foi atribuída à SNABS a responsabilidade da sua coordenação e foram aprovadas as normas básicas para a caracterização, organização e operacionalização do sistema.

Por meio da Portaria Ministerial no 217, de 17/9/1981, foram definidas as competências do Laboratório Nacional de Saúde Pública e foram, na época, credenciados enquanto tal: 0 Instituto Evandro Chagas (Pará); o Laboratório Central da Fundação de Saúde Amaury de Medeiros (Pernambuco); a Fundação Oswaldo Cruz (Rio de Janeiro); o Instituto Adolfo Lutz (São Paulo) e o Instituto de Pesquisas Biológicas (Rio Grande do Sul). Por meio dessa portaria foram também estabelecidas as respectivas áreas de abrangência desses Laboratórios Nacionais.

Com a extinção da SNABS, em decorrência da reforma administrativa promovida em 1990, foram transferidas para a recém-criada Fundação Nacional de Saúde (FNS) as atividades desenvolvidas por aquela secretaria, entre as quais as referentes ao Sistema de Laboratórios de Saúde Pública (Portaria Ministerial no 1331, de 5/1 1/1990).

A Lei no 8.080/90, por meio da qual foi instituído o Sistema Único de Saúde (SUS), determinou que a coordenação da rede nacional de laboratórios está entre as quatro áreas principais de competência da direção nacional desse Sistema. Tal medida tornou clara a necessidade de revisão das normas de organização e operacionalização da rede de laboratórios existente, de forma à adequá-la aos princípios e diretrizes do SUS e, consequientemente, fixar critérios técnicos para nortear o credenciamento dos laboratórios, com destaque para os de referência nacional e regional. Essa necessidade, embora reconhecida pela portaria $\mathrm{n}^{\circ} 699$ de $24 / 6 / 93$, aguarda ainda um ato normativo no sentido de consolidar e aprimorar as ações em curso.

Finalmente, em decorrência da necessidade de implementar o programa de desenvolvimento de uma rede de laboratórios com a participação das secretarias de saúde das unidades federadas, a coordenação do SNLSP, por meio da Portaria Ministerial $n^{9} 1.717$ de $30 / 12 / 93$, foi delegada à uma instância específica (COLAB) do Centro Nacional de Epidemiologia (CENEPI) da FNS.

Em levantamento realizado em 1993 , constatou-se que a rede dispunha de uma unidade por estado, no total de 26 Laboratórios Centrais de Saúde Pública (LACENs), estando em construção a 27: Unidade, no Estado do Tocantins. Aos LACENs estavam ligados mais de 1.200 laboratórios locais. Estes incluíam as unidades laboratoriais voltadas ao diagnóstico das doenças transmitidas por vetores, sob a responsabilidade das Coordenações Regionais da FNS de cada Estado, além de outras 
pertencentes a órgãos que foram incorporados à FNS, tais como as unidades laboratoriais de apoio aos programas de controle das doenças imunopreveníveis da extinta SNABS e ao programa de controle da tuberculose e hanseníase da ex-SNEPS, e os laboratórios de análises clínicas das unidades de saúde e de controle de qualidade da água da ex-FSESP. Esse conjunto passou a compor o núcleo central do SNLSP que, com a Lei no $8.080 / 90$ veio a integrar o Sistema Único de Saúde.

Como outras instâncias da administração pública, a rede nacional de laboratórios sofreu o impacto de problemas que se manifestaram mais agudamente a partir de meados da década de 80 , tais como a falta de uma política de financiamento estável, rupturas e mudanças administrativas freqüentes e a ausência de um arcabouço organizacional integrador entre as instâncias gerenciais de áreas diversas que viesse a substituir a concepção sistêmica então vigente. Apesar de tais intercorrências, os Laboratórios de Saúde Pública continuaram respondendo com relativa eficácia às demandas do sistema de vigilância epidemiológica no suporte ao controle de doenças transmissíveis. Passaram também a receber uma demanda expressiva com o desenvolvimento do programa de controle de DST/AIDS (organizado como Rede Nacional de DST/AIDS - RENADST/AIDS), com o programa de saúde do trabalhador e com o controle analítico de produtos, caracterizando também um maior suporte às ações de vigilância sanitária.

\section{Hierarquização e Funções}

Desde a implantação do Sistema, na década de 70, os Laboratórios de Saúde Pública (LSP) foram organizados de forma hierarquizada, segundo os níveis de complexidade das açốes desenvolvidas em sua concepção original.

Entende-se por "Sistema Nacional de Laboratórios de Saúde Pública" (SNLSP) o conjunto de laboratórios de Saúde Pública pertencentes à União, aos Estados, aos
Municípios e ao Distrito Federal, organizados conforme seu grau de complexidade e hierarquizados por agravos e/ou programas, com a finalidade de desenvolver atividades laboratoriais pertinentes à Vigilância Epidemiológica, Vigilância Sanitária, Saúde do Trabalhador. Foram, assim, identificados cinco níveis de atuação:

\section{Nível Local}

É constituído pelos laboratórios públicos em âmbito municipal, integrados à rede local de serviços para realização de exames básicos e essenciais. São estruturas unitárias que possuem a atribuição de atender às demandas oriundas das necessidades mais comuns da comunidade, buscando a resolubilidade dentro do seu nível de competência (Figura 1).

\section{Nível Regional}

É constituído pelo laboratório executor de ações de maior complexidade demandadas pelo nível local; é organizado em função das necessidades identificadas na sua área de abrangência; deve dar suporte ao nível local no tocante, também, à realização de treinamento de pessoal $\mathrm{e}$ ao repasse de técnicas e normas. Faz parte da Rede Estadual.

\section{Nivel Estadual}

É constituído pelos Laboratórios Centrais dos Estados (LACENs), responsáveis pela definição da política de saúde nessa instância do SUS e pela coordenação das ações laboratoriais no âmbito dos Estados. Têm como atribuiçōes principais o desenvolvimento, a captaçáo, a incorporação e o repasse de tecnologias para a rede estadual, a padronização de novas técnicas e o controle de qualidade, visando à eficiência, à eficácia e à efetividade do Sistema. O LACEN tem como competência coordenar, supervisionar e implementar as atividades da rede estadual, e é considerado o laboratório de referência para os Estados (Figura 2).

O modelo estrutural é inerente ao seu 
grau de complexidade, às necessidades nosológicas e ao controle sanitário da sua área de abrangência. Os setores de um Laboratório de Saúde Pública contemplam: bacteriologia, virologia, imunologia, parasitologia, micologia, química e toxicologia de alimentos, bioquímica, química clínica $\mathrm{e}$ hematológica, análise de águas, de esgotos, de medicamentos, de saneantes e correlatos c outras áreas afins (Figura 3).

\section{Nível Macro-Regional}

É constituido por Laboratórios de Referência Macro-Regionais, considerados pontos de apoio de ordem técnico-operacional de grande utilidade para os serviços de saúde pública das áreas de abrangência, como um clo importante entre a Coordenação do Sistema Nacional de Iaboratórios de Saúde Pública e os Laboratórios Centrais do Estado (LACENs) (Figura 4). Os Laboratórios Centrais reconhecidos como Laboratórios de Referência Macro-Regional têm como atribuiçōes específicas: capacitar recursos humanos dentro da sua respectiva área de abrangência; promover assessoria e supervisão aos Laboratórios Centrais sistematicamente, realizando atividades laboratoriais de maior complexidade e atuando supletivamente em situações de emergência; promover, em conjunto com os Centros de Referência Nacional específicos, a elaboração e a atualização de métodos e técnicas padronizadas; implementar o sistema de controle de resultados em sua respectiva área de abrangência. Não estão conformados de acordo com a distribuição geopolítica, mas "geoepidemiológica". Cita-se como ilustrativo o LACEN do Estado de Mato Grosso do Sul, referência do Instituto Adolfo Lutz.

\section{Nível Nacional}

É constituído pelos laboratórios considerados de exceléncia para doenças ou agravos específicos. Sāo Centros de Referencia Nacional, credenciados para tanto segundo critérios estabelecidos; tem o papel de suporte técnico-científico ao Sistema, e a atribuição de repassar tecnologias e controlar a qualidack. no contexto nacional, $\mathrm{em}$ consonància $\mathrm{com}$ a Coordenação do Sistema Nacional de Laboratórios de Saúde Pública/S.NLSP (Figuras 5 e 6).

Com o advento da Lei no 8080/90, temse discutido o papel dos L.SP além do diagnóstico de apoio ao controle de doenças $\mathrm{e}$ agravos, ao controle de produtos para o consumo humano e à assistência médica individual. Uma das atribuiçōes que vem sendo incentivada e que tem sido desenvolvida pelos I.SPs é a pesquisa en saúde pública para responder às questōes do conhecimento científico e aos avanços tecnológicos. Como exemplo, cita-se a programação de alguns LACENs na identificação de sorotipos e subtipos para o desenvolvimento de novas vacinas.

É preciso repensar o papel do laboratório para o enfrentamento das doenças emergentes e reemergentes. Para tal estão sendo organizadas redes específicas para essas doenças, como: pneumococos, meningococos, influenza, hantavirus, gastroenterites virais, entre outras. A instância nacional tem promovido o desenvolvimento $\mathrm{e}$ intercâmbio técnico-científico com organismos internacionais, estabelecendo referências oficiais. Neste momento, a Coordenação de Laboratórios passa por um processo de revisāo para a atualização das suas normas técnicas e operacionais básicas, conformando-as e adequando-as aos princípios e diretrizes do SUS e introduzindo conceitos inovadores e avançados de biossegurança, boas práticas, informatização e modernização gerencial. 
Figura 1 - Laboratórios Locais/Municipais

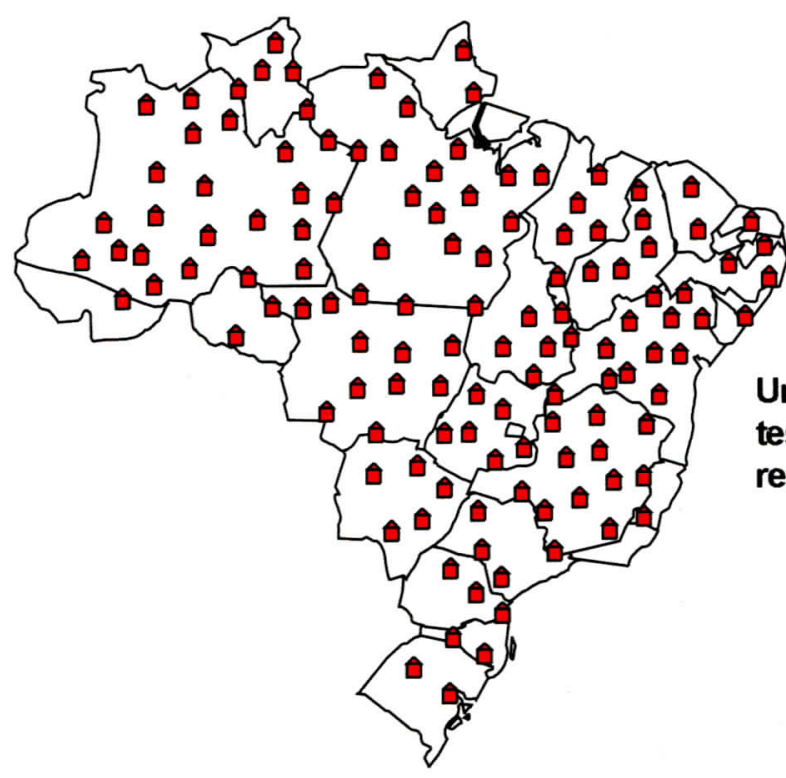

Unidades laboratoriais simples, integrantes da rede local de serviços de saúde, responsáveis pela execução dos exames.

Figura 2 - Laboratórios Centrais (LACENs)

Definindo e organizando a rede estadual de Saúde Pública

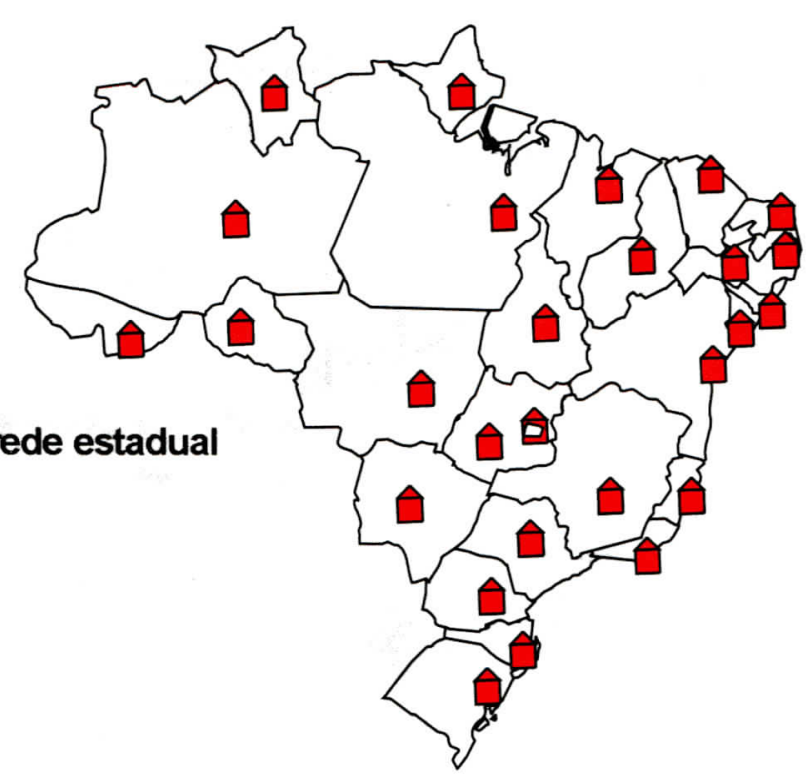


Figura 3 - Organização Básica dos LACENs

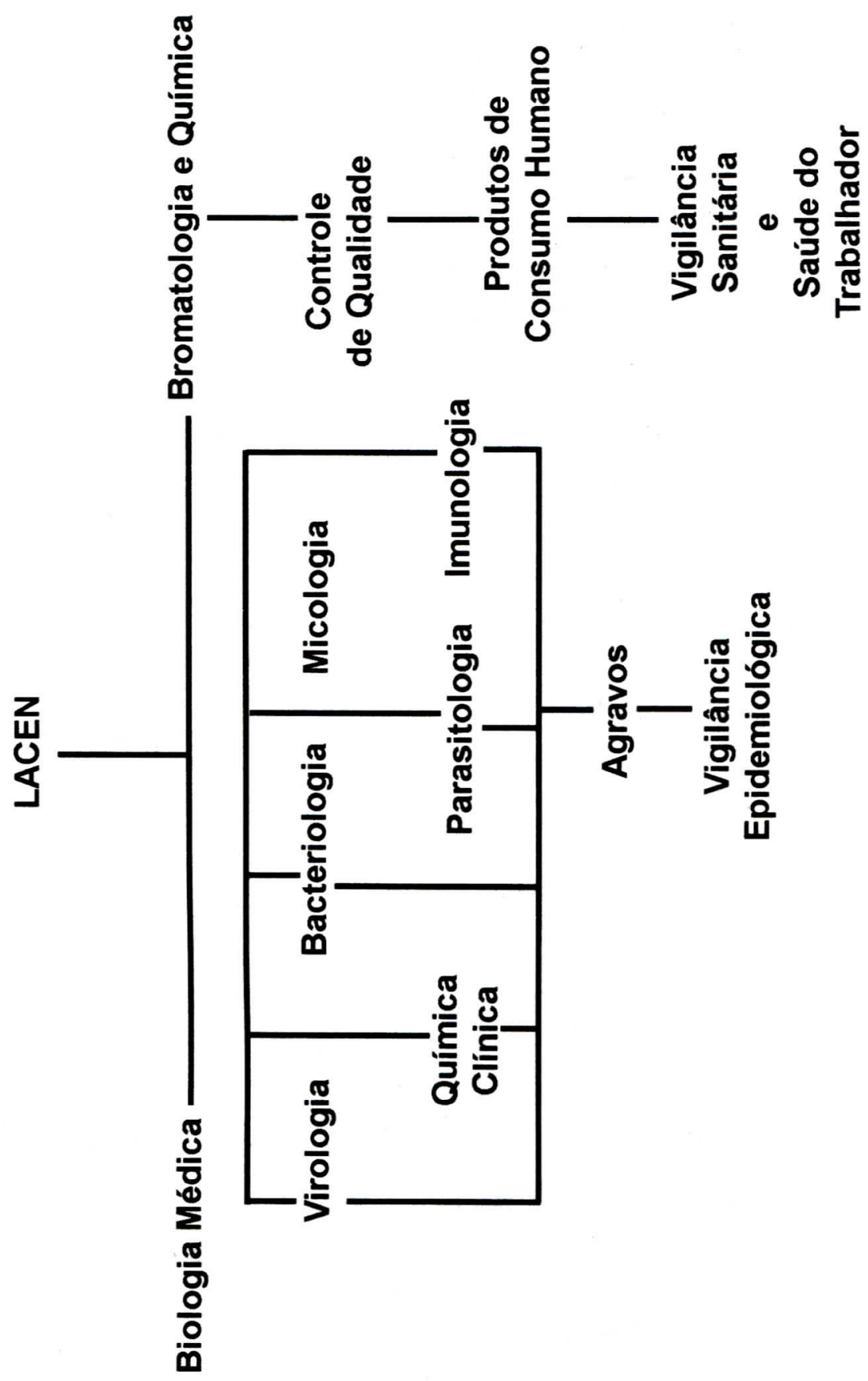


Figura 4 - Laboratórios Macro-regionais

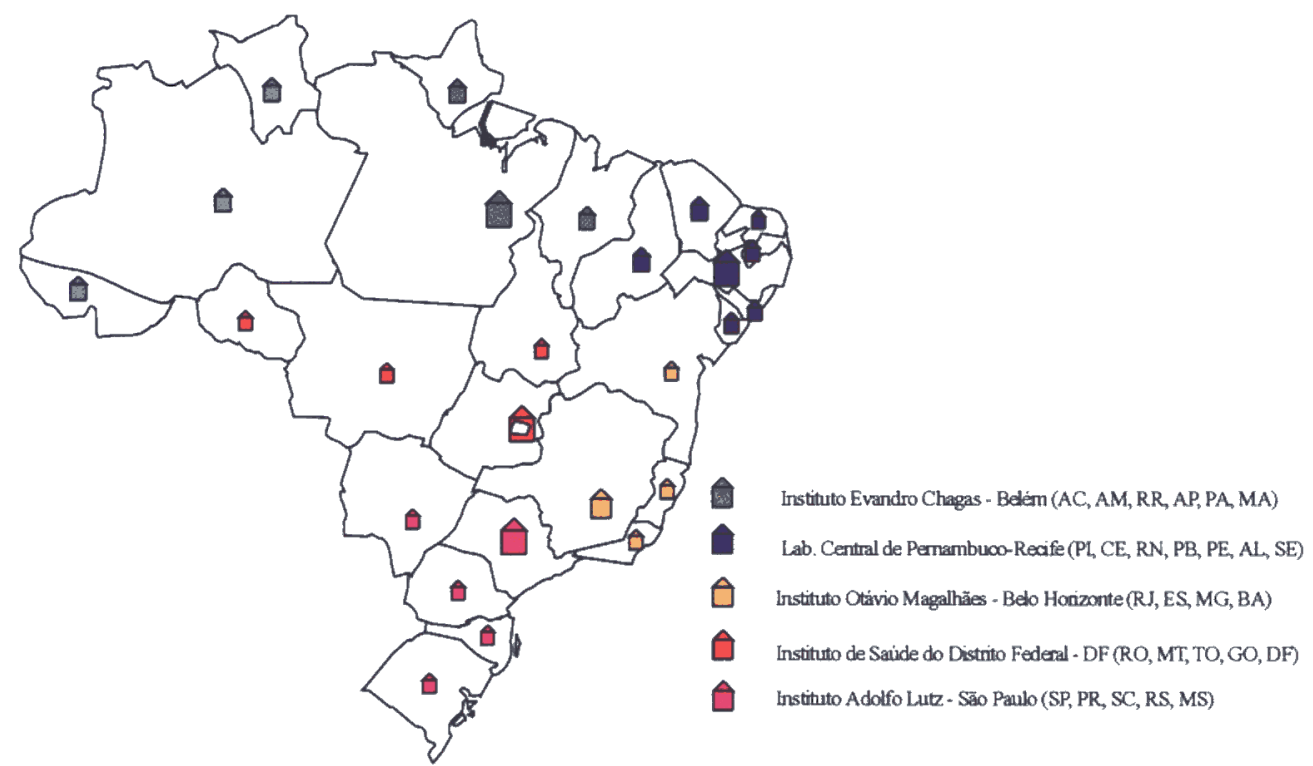

Figura 5 - Centros de Referência Nacional

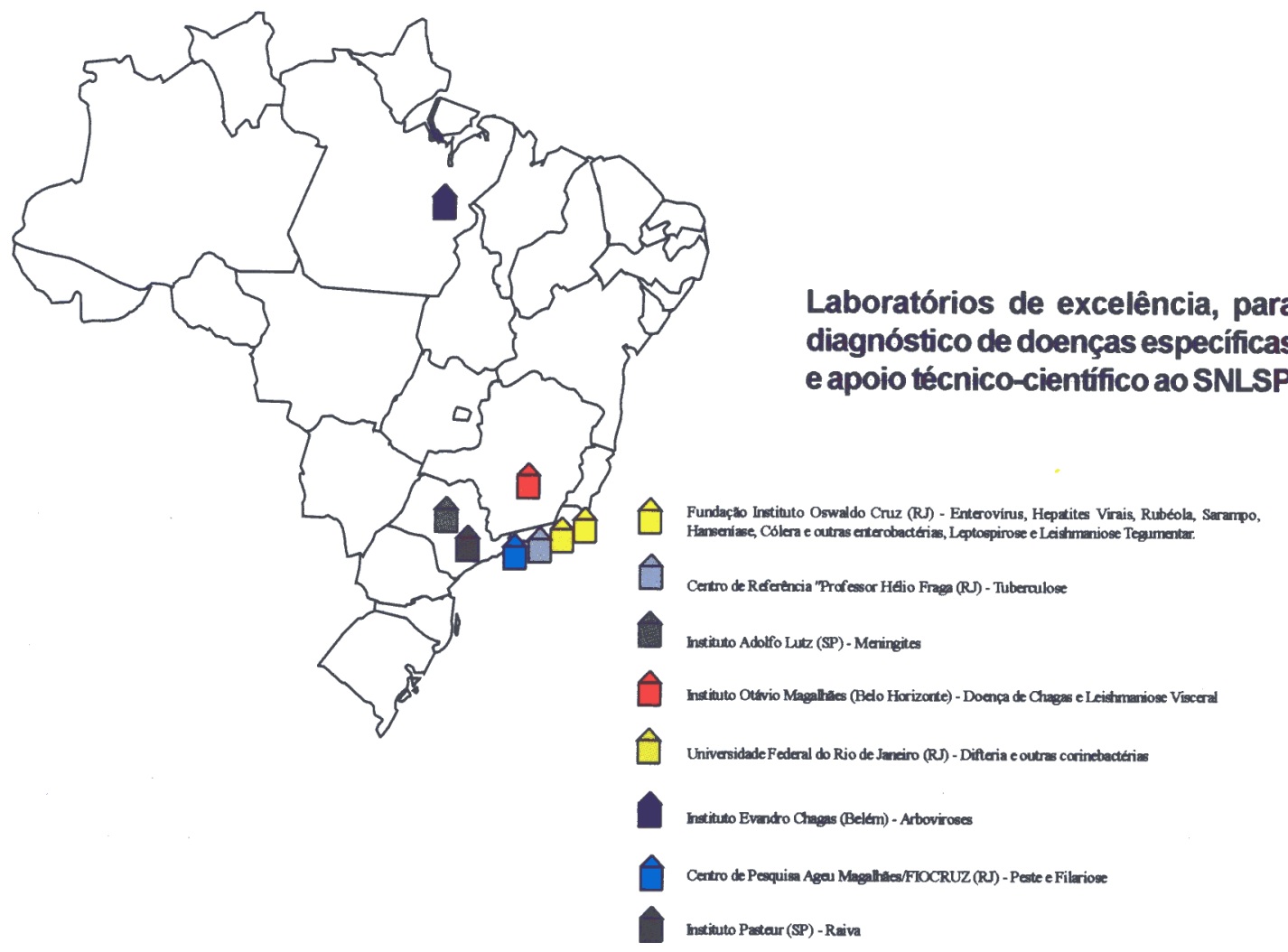

IESUS, VI(2), Abr/Jun, 1997. 
Figura 6 - Sistema Nacional de Laboratórios de Saúde Pública Centros de Referência Nacional

\begin{tabular}{|c|c|c|c|}
\hline $\begin{array}{c}\text { ÁREA DE } \\
\text { REFERENCIA }\end{array}$ & INSTITUIÇÃO & ENDEREÇO & TELEFONES \\
\hline $\begin{array}{l}\text { Cólera e outras } \\
\text { Enterobactérias }\end{array}$ & $\begin{array}{l}\text { Departamento de Bacteriologia } \\
\text { Instituto Oswaldo Cruz/Pavilhão } \\
\text { Rocha Lima/FIOCRUZ }\end{array}$ & $\begin{array}{l}\text { Av. Brasil, 4365-Manguinhos } \\
21.041-220-\text { Rio de Janeiro/R J }\end{array}$ & $\begin{array}{l}(021) 270-6565 \\
(021) 568-4277\end{array}$ \\
\hline $\begin{array}{c}\text { Controle de } \\
\text { Qualidade em } \\
\text { Saúde }\end{array}$ & $\begin{array}{l}\text { Instituto Nacional de Controle de } \\
\text { Qualidade em Saúde (INCQS)/ } \\
\text { FIOCRUZ }\end{array}$ & $\begin{array}{l}\text { Av. Brasil, 4365-Manguinhos } \\
21.041-220-\text { Rio de Janeiro/R J }\end{array}$ & $\begin{array}{l}(021) 260-1290 \\
(021) 290-0392\end{array}$ \\
\hline $\begin{array}{c}\text { Dengue e Febre } \\
\text { Amarela }\end{array}$ & \begin{tabular}{|l|} 
Serviço de Arboviroses \\
Instituto Evandro Chagas / FNS \\
\end{tabular} & $\begin{array}{l}\text { Av. Almirante Barroso, } 492 \\
66.090-000-\text { Belém / PA } \\
\end{array}$ & $\begin{array}{l}(091) 226-6262 \\
091) 246-1022 \\
\end{array}$ \\
\hline $\begin{array}{l}\text { Difieria e outras } \\
\text { Corinebactérias }\end{array}$ & $\begin{array}{l}\text { Departamento de Microbiologia } \\
\text { Medica - Instituto de Microbiologia - } \\
\text { UFRJ }\end{array}$ & $\begin{array}{l}\text { Universidade Federal do Rio de } \\
\text { Janeiro-CQS - Bl. I - Fundāo } \\
21.941-590-\text { Rio de Janeiro/R J } \\
\end{array}$ & $(021) 260-4193$ \\
\hline Doença de Chagas & $\begin{array}{l}\text { Instituto Octávio Magalhāes } \\
\text { Fundação Ezequiel Dias (FUNED) }\end{array}$ & $\begin{array}{l}\text { Rua Conde Pereira Carneiro, } 80 \\
\text { Gameleira } \\
30.510-010-\text { Belo Horizonte/MG } \\
\end{array}$ & $\begin{array}{l}(031) 332-0738 \\
(031) 371-2077\end{array}$ \\
\hline Filariose & $\begin{array}{l}\text { Centro de Pesquisas Ageu Magalhäes / } \\
\text { FIOCR trZ }\end{array}$ & $\begin{array}{l}\text { Campus da Universidade Federal de } \\
\text { Pernambuco } \\
\text { Av. Moraes Rego, s/n }{ }^{\circ} \\
50.670-420-\text { Recife } / \text { PE }\end{array}$ & $(081) 271-4000$ \\
\hline Hanseniase & $\begin{array}{l}\text { L.aboratorio de Hanseníase/ } \\
\text { FIOCRIZ }\end{array}$ & $\begin{array}{l}\text { Av. Brasil, } 4365-M \text { anguinhos } \\
21.041-220-\mathrm{R} \text { io de Janeiro/R J } \\
\end{array}$ & $\begin{array}{l}(021) 598-4297 \\
(021) 598-4289 \\
\end{array}$ \\
\hline Hepatites Virais & $\begin{array}{l}\text { Departamento de Virologia - In stituto } \\
\text { Oswaldo Cruz / FIOCRUZ }\end{array}$ & $\begin{array}{l}\text { Av. Brasil, } 4365-\text { Manguinhos } \\
21.041-220-\text { Rio de Janeiro/R J }\end{array}$ & $(021) 598-4275$ \\
\hline $\begin{array}{l}\text { Leishmaniose } \\
\text { Tegumentar }\end{array}$ & Escola Nacional de Saúde Pública & $\begin{array}{l}\text { Rua Leopoldo Bulhões, } 1480 \\
\text { Bonsucesso } \\
21.041-210-\text { Rio de Jan eiro/R J }\end{array}$ & $\begin{array}{c}(021) 560-3789 \\
\text { Ramal } 208\end{array}$ \\
\hline $\begin{array}{l}\text { Leishmaniose } \\
V \text { isceral }\end{array}$ & Instituto Octávio Magalhāes / FUNED & $\begin{array}{l}\text { Rua Conde Pereira Carneiro, } 80 \\
\text { Gameleira } \\
30.510-010-\text { Belo Horizonte/MG }\end{array}$ & $\begin{array}{l}(031) 332-9738 \\
(031) 371-2077\end{array}$ \\
\hline I.eptospirose & $\begin{array}{l}\text { Departamento de Bacteriologia } \\
\text { Instituto Oswaldo Cruz / FIOCRUZ }\end{array}$ & $\begin{array}{l}\text { Pavilhão Rocha Lima }-4^{\circ} \text { Andar } \\
\text { Av. Brasil, } 4395-\text { Manguinhos } \\
21.045-900-\text { Rio de Janeiro/RJ }\end{array}$ & $\begin{array}{l}(021) 270-6595 \\
(021) 580-4283\end{array}$ \\
\hline Meningites & $\begin{array}{l}\text { Laboratório de Microbiologia - } \\
\text { Instituto Adolfo Lutz (IAL) }\end{array}$ & $\begin{array}{l}\text { Av. Dr. Arnaldo, } 355-\text { Cerqueira } \\
\text { César } \\
01.246-902-\text { São Paulo/SP } \\
\end{array}$ & $\begin{array}{l}(011) 3011-0111 \\
(011) 853-7022\end{array}$ \\
\hline Peste & $\begin{array}{l}\text { Centro de Pesquisas Ageu Magalhães / } \\
\text { FIOCR UZ }\end{array}$ & $\begin{array}{l}\text { Campus da Universidade Federal de } \\
\text { Pernambuco } \\
\text { Av. Moraes Rego, s/n } \\
50.670-420 \text { - Recife/PE }\end{array}$ & $(081) 271-4000$ \\
\hline Poliom ielite & $\begin{array}{l}\text { Laboratório de Virologia - Instituto } \\
\text { Oswaldo Cruz / FIOCRUZ }\end{array}$ & \begin{tabular}{|l|} 
Av. Brasil, $4365-$ Manguinhos \\
21.041-220-Rio de Janeiro/RJ
\end{tabular} & $\begin{array}{l}(021) 230-7638 \\
(021) 598-4189 \\
\end{array}$ \\
\hline Sarampo & $\begin{array}{l}\text { Departamento de Virologia - Instituto } \\
\text { Oswaldo Cruz / FIO CRUZ }\end{array}$ & $\begin{array}{l}\text { Pavilhão Rocha Lima }-4^{\circ} \text { Andar } \\
\text { Av. Brasil, 4395-Manguinhos } \\
21.045-900-\text { Rio de Janeiro/RJ }\end{array}$ & $\begin{array}{l}(021) 598-4353 \\
(021) 598-4360\end{array}$ \\
\hline Tuberculose & $\begin{array}{l}\text { Centro de Referência Prof. Hélio } \\
\text { Fraga / FNS }\end{array}$ & $\begin{array}{l}\text { Estrada de Curicica, } 2000 \\
22.710-550-\text { Rio de Janeiro/RJ } \\
\end{array}$ & $(021) 445-6848$ \\
\hline $\begin{array}{l}\text { Reativos para } \\
\text { Diagnóstico } \\
\text { Laboratorial }\end{array}$ & $\begin{array}{l}\text { Laboratório de Reativos / Instituto } \\
\text { Bio-Manguinhos / FIOCR UZ }\end{array}$ & $\begin{array}{l}\text { Av. Brasil, 4395-Manguinhos } \\
21.041-220-\text { Rio de Janeiro/RJ }\end{array}$ & $\begin{array}{l}021) 598-4284 \\
(021) 260-2344\end{array}$ \\
\hline Influenza & $\begin{array}{l}\text { Laboratório de Virologia - Instituto } \\
\text { A dolfo Lutz (IAL) }\end{array}$ & $\begin{array}{l}\text { Av. Dr. Arnaldo, } 355 \text { - Cerqueira } \\
\text { César } \\
01.246-902-\text { São Paulo/SP } \\
\end{array}$ & $\begin{array}{l}(011) 3011-0111 \\
(011) 853-7022\end{array}$ \\
\hline Arbovírus & Instituto Evandro Chagas / FNS & $\begin{array}{l}\text { Av. Almirante Barroso, } 492 \\
\text { 66.090-000-Belém/PA } \\
\end{array}$ & $\begin{array}{l}(091) 226-6262 \\
(091) 246-1022 \\
\end{array}$ \\
\hline Sarampo & Instituto Oswaldo Cruz / FIOCRUZ & $\begin{array}{l}\text { Pavilhão Rocha Lima }-4^{\circ} \text { Andar } \\
\text { Av. Brasil, 4395 - Manguinhos } \\
21.045-900-\text { Rio de Janeiro/RJ }\end{array}$ & $\begin{array}{l}(021) 598-4353 \\
(021) 598-4360\end{array}$ \\
\hline
\end{tabular}

